Article

\title{
Rumen Fermentation Characteristics in Pre- and Post-Weaning Calves upon Feeding with Mulberry Leaf Flavonoids and Candida tropicalis Individually or in Combination as a Supplement
}

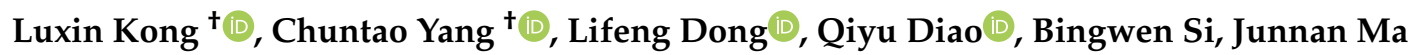 \\ and Yan Tu*iD
}

Feed Research Institute, Chinese Academy of Agricultural Sciences, Key Laboratory of Feed Biotechnology of the Ministry of Agriculture and Rural Affairs, Beijing Key Laboratory for Dairy Cow Nutrition,

Beijing 100081, China; kongluxin@caas.cn (L.K.); yangchuntao0808@163.com (C.Y.); donglifeng@caas.cn (L.D.); diaoqiyu@caas.cn (Q.D.); sibingwen@caas.cn (B.S.); manan014@163.com (J.M.)

* Correspondence: tuyan@caas.cn

t The two authors contribute equally to this work.

Received: 25 October 2019; Accepted: 15 November 2019; Published: 18 November 2019

Simple Summary: Supplementing diets with yeast or yeast cultures is recognized as a common practice in modern dairy farming because of the positive effects of yeast on production, health, and immunity performance in ruminants. Recent studies have demonstrated that supplementation with Candida tropicalis has potential benefits by improving fibrous material digestion and antioxidant function, and enhancing the microbial activities in the rumen. Meanwhile, flavonoids, as secondary plant metabolites, are ubiquitously present in plants used for livestock feed, have health-promoting properties, including antioxidative, anti-inflammatory, and metabolic effects. However, in practice, supplementation with monostrain probiotics or individual additives has not enhanced production as expected. Therefore, we hypothesize that multispecies probiotics or the combination of yeast and phytochemicals could be compatible with each other and act synergistically. The results showed that supplementation with $C$. tropicalis or flavonoids improved rumen fermentation, but supplementation with C. tropicalis had limited effects on increasing growth performance and decreasing fecal scores compared with flavonoid supplementation. However, the combination of $C$. tropicalis and flavonoids did not show a synergistic effect on health or rumen fermentation compared with use of flavonoids alone in pre- and post-weaning calves.

Abstract: Although flavonoids or yeast have been used as feed additives to improve the production efficiency and health of adult cattle, little information is available on their effects on rumen fermentation in calves. The objective of this study was to investigate the effects of feed supplementation with mulberry leaf flavonoids and Candida tropicalis on performance, blood parameters, and rumen fermentation characteristics during pre-weaning and post-weaning periods. Forty-eight Holstein calves were used in a four-groups trial and were supplemented with (1) no yeast or flavonoids (CON), (2) active dry yeast (ADY; C. tropicalis, $5.0 \times 10^{9} \mathrm{CFU} / \mathrm{d}$ ), (3) flavonoids (FLA; $3 \mathrm{~g} / \mathrm{d}$ ), or (4) yeast and flavonoids (YF; C. tropicalis, $5.0 \times 10^{9} \mathrm{CFU} / \mathrm{d}$; flavonoids, $3 \mathrm{~g} / \mathrm{d}$ ). The feeding strategy was as follows: milk replacer was offered at $12 \%$ of body weight in two meals per calf each day at age $21 \mathrm{~d}$, and a gradual weaning process was adopted at age 50 to 56 days. Data of daily feed intake, body weight, and serum and rumen fermentation parameters were obtained at 28, 42,56, and $80 \mathrm{~d}$ ages, respectively. A significant time effect and interaction between treatment and time was found for average daily gain, feed efficiency, total volatile fatty acid concentration, and proportion of propionate in calves $(p<0.05)$. Average daily gain and feed efficiency increased during post-weaning and overall periods for calves in FLA and YF groups compared with CON and ADY groups $(p<0.05)$. A reduction of fecal scores with 
supplementation was found in FLA and YF groups $(p<0.05)$. Rumen fluid $\mathrm{pH}$ and ammonia nitrogen concentration remained constant across the groups, whereas total volatile fatty acid concentration and molar proportion of propionate significantly increased during the pre-weaning and overall periods in FLA and YF groups $(p<0.05)$. Calves in YF group had the highest serum concentrations of IgG and IgA during the overall period $(p<0.05)$. Additionally, serum $\beta$-hydroxybutyric acid concentration was higher in ADY and FLA groups during the post-weaning period $(p<0.05)$. Supplementation with $C$. tropicalis showed little effect on increasing growth performance and health compared with flavonoids alone. Meanwhile, the combination of $C$. tropicalis and flavonoids was not synergistic with respect to improving health and rumen fermentation compared with use of flavonoids alone in preand post-weaning calves $(p>0.05)$.

Keywords: Candida tropicalis; growth performance; mulberry leaf flavonoid; rumen fermentation characteristics

\section{Introduction}

Incorporation of yeast and yeast cultures into the diets of ruminants is recognized as a common practice in modern dairy farming because yeast has positive effects on production, health, and immunity performance [1]. Unlike Saccharomyces cerevisiae, Candida tropicalis is an opportunistic pathogen that causes disease [2,3]. However, publications have reported that $C$. tropicalis is commonly detected in the gastrointestinal tract of healthy humans [4,5] and has no harmful effects on animal health [6]. Furthermore, recent studies demonstrated that supplementation with $C$. tropicalis has potential benefits by improving fibrous material digestion and antioxidant function, and enhancing the microbial activities in the rumen $[7,8]$. Moreover, some studies have shown that supplementation with monostrain probiotics does not positively influence animals because such probiotics have little chance to colonize the gastrointestinal tract [9] or control multifactorial diseases [10]. Timmerman et al. [9] observed that strains used in multistrain, multispecies probiotics or the combination of yeast and phytochemicals are compatible with each other and act synergistically.

Phytochemicals may have potential health benefits for animals and can serve as alternatives to pharmaceuticals $[11,12]$. Mulberry leaves have been traditionally considered as an alternative high-quality feed for farm animals in China, owing to their high nutritive value as well as their flavonoid contents [13]. Recent studies have demonstrated that mulberry-derived flavonoids have the potential to enhance or stabilize animal performance and health [14,15]. Flavonoids are secondary plant metabolites and are ubiquitously present in plants used for livestock feed [16]. Many plant-derived extracts, which contain considerable amounts of various flavonoids, have health-promoting properties (e.g., antioxidative, anti-inflammatory, and metabolic effects), as well as other functional characteristics, such as modulating the expression and activities of several enzymes involved in lipid and carbohydrate metabolism $[17,18]$. Therefore, we hypothesized that the combined use of $C$. tropicalis and flavonoids would have greater effects on the growth performance, health, and rumen fermentation characteristics of pre- and post-weaning calves compared with the use of either supplement alone.

\section{Materials and Methods}

\subsection{Flavonoids and Active Dry Yeast}

The natural flavonoids extracted from Mulberry (Morus alba) leaves were obtained from Xi'an Feida Bio-Tech (Shanxi, China). The main components ( $\mathrm{wt} / \mathrm{wt}$ ) were flavones $(65.0 \%)$, flavonols $(20 \%)$, and other polyphenols (15.0\%) that share a common flavan core (15 carbon atoms). Active dry yeast (C. tropicalis, $5.0 \times 10^{9} \mathrm{CFU} / \mathrm{g}$ ) was purchased from Huanong Biological Engineering (Beijing, China). Before commencement of animal trials, the number of viable cells in $1 \mathrm{~g}$ of dehydrated active dry yeast 
was determined by plating cells on yeast extract peptone dextrose agar at $37^{\circ} \mathrm{C}$. The active dry yeasts were kept at $4^{\circ} \mathrm{C}$, and viable cells were examined weekly to ensure their stability.

\subsection{Animals, Diets, and Experimental Design}

This study was conducted at a commercial dairy farm (Sanyuan Co., Beijing, China) in compliance with the animal protection regulations approved by the Animal Ethics Committee of the Chinese Academy of Agricultural Sciences (with protocol FRI-CAAS-20140812).

A total of 48 Chinese Holstein bull calves with mean body weight of (BW) $46 \pm 5.9 \mathrm{~kg}$ were randomly allocated to one of four experimental groups from age 21 to $80 \mathrm{~d}$. All calves were fed the same diet before age $28 \mathrm{~d}$. Each group had 12 replicates, with 1 calf per replicate. Calves from the four groups at age $28 \mathrm{~d}$ were supplemented with (1) no yeast or flavonoids (CON), (2) C. tropicalis (ADY; $1 \mathrm{~g} /$ calf per day), (3) flavonoids (FLA; $3 \mathrm{~g} /$ calf per day), or (4) C. tropicalis and flavonoids (YF; C. tropicalis, $5.0 \times 10^{9} \mathrm{CFU} / \mathrm{d}$; flavonoids, $\left.3 \mathrm{~g} / \mathrm{d}\right)$. Milk replacer (12\% BW per calf per day; Table 1) was offered twice daily at 08:00 and 16:00 before weaning. The weaning process commenced at age $50 \mathrm{~d}$ and milk replacer was gradually replaced with starter until age $56 \mathrm{~d}$. The flavonoids dose was calculated based on our previous results [13] and was equivalent to $65 \mathrm{mg}$ of flavonoids $/ \mathrm{kg}$ of BW. The dose of active dry yeast used in the present study was calculated based on the results in dairy cows observed by Chung et al. [19] and Jing et al. [20]. During the pre-weaning period, the supplement was individually mixed with milk replacer liquid and fed directly to the calves in the morning feeding. During the post-weaning period, the supplement was individually hand-mixed with $100 \mathrm{~g}$ of starter to ensure that all the supplement had been consumed, and then more starters were subsequently fed to individual calves. The ingredients of the starter (as \% of dry matter, DM) were corn (20\%), extruded corn $(22.9 \%)$, soybean meal $(20 \%)$, extruded soybean $(18 \%)$, dried whey $(5 \%)$, wheat bran $(10 \%)$, calcium hydrogen phosphate $(0.8 \%)$, limestone $(1.8 \%)$, salt $(0.5 \%)$, and premix $(1 \%)$. The compositions of premix (per kilogram of starter) were vitamin A (15,000 IU), vitamin D (5000 IU), vitamin E (50 mg), Fe (90 mg), Cu (12.5 mg), Mn (30 mg), Zn (90 mg), Se (0.3 mg), I (1.0 mg), and Co (0.5 mg). The milk replacer (patent for invention, $\mathrm{CN}$ 02128844.5) was provided by the Beijing Precision Animal Nutrition Research Center (Beijing, China). The chemical compositions of starter and milk replacer are showed in Table 1. Clean, fresh water and dry pelleted starter were provided ad libitum throughout the trial. Calves were housed in individual pens $\left(3.0 \mathrm{~m} \times 1.2 \mathrm{~m}, 3.6 \mathrm{~m}^{2} /\right.$ animal $)$ surrounded by fencing $(1.1 \mathrm{~m}$ high). Two metal supports were attached to the side of the fence to support feeders.

Table 1. Chemical composition (\% of dry matter basis) of starter and milk replacer used in the present study.

\begin{tabular}{ccc}
\hline Item & Starter & Milk Replacer \\
\hline Dry matter, \% as fed & 85.36 & 95.36 \\
Organic matter & 92.21 & 94.85 \\
Crude protein & 19.08 & 24.27 \\
Gross energy, MJ/kg of DM & 15.45 & 19.86 \\
Neutral detergent fiber & 18.59 & 4.02 \\
Acid detergent fiber & 10.65 & 2.11 \\
Ether extract & 2.21 & 12.85 \\
Calcium & 1.09 & 1.07 \\
Phosphorus & 0.47 & 0.48 \\
\hline
\end{tabular}

\subsection{Measurements, Sample Collection, and Analysis}

Throughout the experiment, the intakes of milk replacer and starters for each calf were recorded daily, and representative feed samples were collected weekly and frozen at $-20{ }^{\circ} \mathrm{C}$ for subsequent analyses. The BW of each calf was recorded at ages $28,42,56$, and $80 \mathrm{~d}$ to calculate average daily gain (ADG) and feed efficiency. Fecal consistency was scored daily during the morning milk feeding using a 1 to 4 scale according to Heinrichs et al. [21]. Fecal score $>2$ for 3 consecutive days was considered to 
reflect diarrhea. In this trial, only a subset of calves ( $n=7$ per group) with BW similar to the group average were considered for blood variable and rumen fermentation parameter analyses. Blood samples were taken by jugular venipuncture at ages $28,42,56$, and $80 \mathrm{~d}$ before the morning feeding. Afterward, serum was recovered by centrifugation for analysis of blood metabolite parameters. The concentrations of IgG, IgA, IgM, and epidermal growth factor (EGF) were determined by ELISA using cow IgA, IgG, IgM, and EGF kits from Bethyl Laboratories (Montgomery, TX, USA). The $\beta$-hydroxybutyric acid (BHBA) concentration was measured using a BHBA dehydrogenase reagent kit (310-UV, Sigma, St. Louis, MO, USA). Rumen fluid was collected at ages of $28,42,56$, and $80 \mathrm{~d}$ using a copper probe (length $5 \mathrm{~cm}$, internal diameter $1 \mathrm{~cm}$ ) attached to a plastic tube, protected by stainless steel springs and designed specifically for calves. The probe was inserted into the mouth of the calf and fed down the rumen. A 200-mL syringe was used to withdraw rumen fluid. The first $50 \mathrm{~mL}$ of fluid was discarded, and subsequent fluid was collected. Rumen fluid $\mathrm{pH}$ was immediately determined using a handheld pH meter that was calibrated before each reading (Testo 205, Testo AG, Lenzkirch, Germany). Rumen fluid samples were strained through four layers of cheesecloth to remove large feed particles. Samples for ammonia $\mathrm{N}$ concentration $\left(\mathrm{NH}_{3}-\mathrm{N}\right)$ analyses were preserved by mixing $5 \mathrm{~mL}$ filtered rumen fluid with $5 \mathrm{~mL}$ of $0.2 \mathrm{M} \mathrm{HCl}$; samples for analysis of volatile fatty acid (VFA) concentrations were prepared by mixing $5 \mathrm{~mL}$ filtered rumen fluid with $1 \mathrm{~mL}$ of $0.5 \mathrm{M} \mathrm{H}_{2} \mathrm{SO}_{4}$. The concentration of $\mathrm{NH}_{3}-\mathrm{N}$ was determined using the methods described by Dong et al. [22]. Individual and total VFA concentrations in aliquots of rumen fluid were determined with a flame ionization detector in a gas chromatograph (GC522, Wufeng Instruments, Shanghai, China), using a 15-mL semi-capillary glass column $(0.53 \mathrm{~mm}$ in diameter) packed with Chromosorb 101 (Johns-Monville, Denver, CO, USA), with $\mathrm{N}_{2}$ as carrier gas at a column temperature of $120^{\circ} \mathrm{C}$ [23].

\subsection{Statistical Analysis}

Data was analyzed separately for the pre-weaning period (age 28 to $50 \mathrm{~d}$ ), post-weaning period (age 56 to $80 \mathrm{~d}$ ), and overall period (age 28 to $80 \mathrm{~d}$ ). Data for growth performance, serum, and rumen fermentation were analyzed as a randomized complete design. Fecal scores were pooled by week for analysis. A repeated-measure ANOVA was conducted using the Mixed procedure in SAS (Statistical Analysis System) software version 9.2 (SAS Institute Inc., Cary, NC, USA), based on the statistical model:

$$
\mathrm{Y}_{\mathrm{ijk}}=\mu+\mathrm{T}_{\mathrm{i}}+\mathrm{D}_{\mathrm{j}}+(\mathrm{TD})_{\mathrm{ij}}+\mathrm{C}_{(\mathrm{i}) \mathrm{k}}+\mathrm{e}_{(\mathrm{ij}) \mathrm{k}}
$$

where $Y_{\mathrm{ijk}}=$ dependent variable, $\mu$ overall mean, $T_{i}=$ fixed effect of treatment $(I=1,2,3,4), D_{j}=$ fixed effect of day $(\mathrm{j}=28,42,56,80)$, (TD $)_{\mathrm{ij}}=$ fixed interaction of treatment and day, $\mathrm{C}_{(\mathrm{i}) \mathrm{k}}=$ random effect of each calf within the group, and $\mathrm{e}_{(\mathrm{ij}) \mathrm{k}}=$ residual error.

The AR (Autoregressive model) (1) covariance structures were used based on model fit, day (week) was the repeated variable, and calf by treatment was the subject. Denominator degrees of freedom were adjusted by the Kenward-Rogers method. Significance was declared at $p<0.05$ and the comparison of the means was carried out with the LSD test.

\section{Results}

\subsection{Intake, Growth Performance, and Fecal Score}

Throughout the study, the effect of treatment or treatment $\times$ time was not observed for feed DM intake (milk replacer or starter) $(p>0.05$, Table 2). However, a significant difference was detected among groups for ADG and feed efficiency (daily gain/daily DM intake, $\mathrm{kg} / \mathrm{kg}$ ) during post-weaning and overall periods $(p<0.05)$. The ADG of calves was greater in FLA and YF groups compared with CON and ADY groups during the post-weaning period $(0.77$ and 0.79 vs. 0.69 and $0.70 \mathrm{~kg} / \mathrm{d} ; p<0.05$ ) and overall period $(0.63$ and 0.64 vs. 0.58 and $0.60 \mathrm{~kg} / \mathrm{d} ; p<0.05)$. During the post-weaning period, feed efficiency was higher in the ADY and FLA groups, followed by the YF and CON groups $(p<0.05)$, and it was greater in FLA group than that of YF and CON groups during the overall period $(p<0.05)$. 
Treatment and time affected fecal score (treatment, time, $p<0.05$ ) during the pre-weaning, with lower (treatment, $p=0.039$ ) score in FLA and YF groups compared with CON group.

Table 2. Effects of supplementation with Candida tropicalis and mulberry leaf flavonoids individually or in combination on growth performance and fecal scores in Holstein calves during pre-weaning, post-weaning, and overall periods.

\begin{tabular}{|c|c|c|c|c|c|c|c|c|}
\hline \multirow{2}{*}{ Item $^{1}$} & \multicolumn{4}{|c|}{ Treatment $^{2}$} & \multirow{2}{*}{ SEM $^{3}$} & \multicolumn{3}{|c|}{$p$-Value } \\
\hline & $\mathrm{CON}$ & ADY & FLA & YF & & Treatment & Time & Treatment $\times$ Time \\
\hline \multicolumn{9}{|l|}{ DM intake, $\mathrm{kg} / \mathrm{d}$} \\
\hline \multicolumn{9}{|l|}{ Milk replacer } \\
\hline Pre-weaning & 0.76 & 0.76 & 0.78 & 0.77 & 0.02 & 0.618 & 0.445 & 0.592 \\
\hline \multicolumn{9}{|l|}{ Starter } \\
\hline Pre-weaning & 0.25 & 0.27 & 0.27 & 0.30 & 0.02 & 0.221 & 0.194 & 0.217 \\
\hline Post-weaning & 1.40 & 1.49 & 1.51 & 1.65 & 0.03 & 0.130 & 0.691 & 0.541 \\
\hline Overall & 0.96 & 0.99 & 1.02 & 1.11 & 0.02 & 0.205 & 0.427 & 0.313 \\
\hline \multicolumn{9}{|l|}{ Total DMI, kg/d } \\
\hline Pre-weaning & 1.00 & 1.03 & 1.05 & 1.08 & 0.02 & 0.124 & 0.242 & 0.121 \\
\hline Overall & 1.12 & 1.13 & 1.16 & 1.22 & 0.02 & 0.212 & 0.117 & 0.422 \\
\hline \multicolumn{9}{|c|}{ Average daily gain, $\mathrm{kg} / \mathrm{d}$} \\
\hline Pre-weaning & 0.48 & 0.51 & 0.48 & 0.50 & 0.03 & 0.134 & 0.281 & 0.226 \\
\hline Post-weaning & $0.69^{b}$ & $0.70^{\mathrm{b}}$ & $0.77^{\mathrm{a}}$ & $0.79^{a}$ & 0.02 & 0.032 & 0.028 & 0.032 \\
\hline Overall & $0.58^{\mathrm{b}}$ & $0.60^{\mathrm{ab}}$ & $0.63^{a}$ & $0.64^{\mathrm{a}}$ & 0.03 & 0.011 & 0.028 & 0.013 \\
\hline \multicolumn{9}{|c|}{ Feed efficiency, kg/kg } \\
\hline Pre-weaning & 0.51 & 0.53 & 0.56 & 0.53 & 0.01 & 0.286 & 0.226 & 0.100 \\
\hline Post-weaning & $0.47^{\mathrm{b}}$ & $0.55^{\mathrm{a}}$ & $0.55^{\mathrm{a}}$ & $0.50^{b}$ & 0.02 & 0.031 & 0.034 & 0.025 \\
\hline Overall & $0.50^{\mathrm{b}}$ & $0.54^{\mathrm{a}}$ & $0.55^{\mathrm{a}}$ & $0.51^{b}$ & 0.01 & 0.012 & 0.032 & 0.017 \\
\hline \multicolumn{9}{|l|}{ Fecal score } \\
\hline Pre-weaning & $1.53^{\mathrm{a}}$ & $1.45^{\mathrm{ab}}$ & $1.42^{b}$ & $1.42^{\mathrm{b}}$ & 0.03 & 0.039 & 0.008 & 0.125 \\
\hline Post-weaning & 1.26 & 1.19 & 1.14 & 1.16 & 0.02 & 0.325 & 0.032 & 0.742 \\
\hline Overall & 1.39 & 1.30 & 1.29 & 1.30 & 0.02 & 0.073 & 0.025 & 0.513 \\
\hline
\end{tabular}

${ }^{a, b}$ Mean values within a row with different superscripts differ significantly $(p<0.05) .{ }^{1}$ Pre- and post-weaning: calves were given treatments from 28 to $50 \mathrm{~d}$ of age and from 56 to $80 \mathrm{~d}$ of age. Overall: calves were given treatments from 28 to $80 \mathrm{~d}$ of age. $\mathrm{DMI}=$ dry matter intake. Feed efficiency $=$ daily gain/daily total DM intake. ${ }^{2} \mathrm{CON}=$ no yeast or flavonoids fed; ADY = Candida tropicalis as supplement; FLA = mulberry leaf flavonoids as supplement; $\mathrm{YF}=$ combination of Candida tropicalis and mulberry leaf flavonoids as supplement. ${ }^{3} \mathrm{SEM}=$ standard error of the mean.

\subsection{Rumen Fermentation Characteristics}

Rumen fluid $\mathrm{pH}$ and $\mathrm{NH}_{3}-\mathrm{N}$ concentration across groups were similar during the pre-weaning, post-weaning, and overall periods ( $p>0.05$, Table 3$)$. Total VFA concentrations in the YF group were higher $(p<0.05)$, especially at age $42 \mathrm{~d}$ (Figure $1 \mathrm{a})$, compared with that in the CON and ADY groups during the pre-weaning and overall periods, whereas VFA concentration was similar among groups during the post-weaning period $(p>0.05)$. Calves in the YF group had a higher molar proportion of propionate (especially at age $42 \mathrm{~d}$; Figure $1 \mathrm{~b}$ ) and lower acetate/propionate ratio compared with the CON group during the pre-weaning $(p<0.05)$ and overall $(p<0.05)$ periods. Additionally, calves fed yeast, flavonoids, or both have a higher molar proportion of butyrate at age $80 \mathrm{~d}(p<0.05$; Figure 1c), and this tendency was high compared with CON calves during the post-weaning period $(p=0.055)$. 
Table 3. Effects of supplementation with Candida tropicalis and mulberry leaf flavonoids individually or in combination on rumen fermentation parameters in Holstein calves during pre-weaning, post-weaning, and overall periods.

\begin{tabular}{|c|c|c|c|c|c|c|c|c|}
\hline Item $^{1}$ & \multicolumn{4}{|c|}{ Treatment $^{2}$} & SEM $^{3}$ & \multicolumn{3}{|c|}{$p$-Value } \\
\hline \multicolumn{9}{|l|}{$\mathrm{pH}$} \\
\hline Pre-weaning & 6.2 & 6.5 & 6.3 & 6.3 & 0.8 & 0.213 & 0.565 & 0.182 \\
\hline Post-weaning & 6.2 & 6.4 & 6.4 & 6.3 & 0.7 & 0.397 & 0.020 & 0.191 \\
\hline Overall & 6.1 & 6.4 & 6.3 & 6.3 & 0.7 & 0.265 & 0.154 & 0.290 \\
\hline Post-weaning & 7.52 & 7.36 & 7.40 & 7.33 & 1.05 & 0.340 & 0.280 & 0.316 \\
\hline Overall & 5.49 & 5.42 & 5.47 & 5.18 & 1.92 & 0.213 & 0.342 & 0.253 \\
\hline \multicolumn{9}{|c|}{ Total VFA, mmol/L } \\
\hline Pre-weaning & $44.20^{b}$ & $49.99^{b}$ & $57.81^{a}$ & $60.90^{\mathrm{a}}$ & 3.21 & 0.027 & 0.018 & 0.014 \\
\hline Post-weaning & 75.96 & 81.45 & 71.27 & 83.85 & 5.27 & 0.253 & 0.561 & 0.316 \\
\hline Post-weaning & 55.13 & 56.75 & 52.50 & 58.75 & 2.12 & 0.208 & 0.466 & 0.446 \\
\hline Overall & 54.14 & 54.36 & 56.21 & 55.79 & 2.04 & 0.849 & 0.617 & 0.559 \\
\hline \multicolumn{9}{|c|}{ Propionate/total VFA, \% } \\
\hline Pre-weaning & $24.20^{b}$ & $25.40^{\mathrm{b}}$ & $29.50^{a b}$ & $32.83^{\mathrm{a}}$ & 2.92 & 0.047 & 0.036 & 0.038 \\
\hline Post-weaning & $24.09^{b}$ & $29.50^{a}$ & $30.13^{a}$ & $30.50^{\mathrm{a}}$ & 1.64 & 0.045 & 0.747 & 0.838 \\
\hline Overall & $24.13^{b}$ & $27.92^{\mathrm{ab}}$ & $29.86^{a b}$ & $31.50^{\mathrm{a}}$ & 1.84 & 0.018 & 0.026 & 0.017 \\
\hline \multicolumn{9}{|c|}{ Butyrate/total VFA, \% } \\
\hline Pre-weaning & 6.40 & 8.60 & 6.83 & 7.00 & 1.16 & 0.455 & 0.108 & 0.740 \\
\hline Post-weaning & 6.63 & 9.75 & 13.25 & 11.38 & 1.87 & 0.055 & 0.337 & 0.839 \\
\hline Overall & 6.54 & 9.31 & 10.50 & 9.50 & 1.07 & 0.193 & 0.004 & 0.669 \\
\hline \multicolumn{9}{|c|}{ Acetate/propionate ratio } \\
\hline
\end{tabular}

a,b Mean values within a row with different superscripts differ significantly $(p<0.05) .{ }^{1}$ Pre- and post-weaning: calves were given treatments at ages 28 and $42 \mathrm{~d}$, and at ages 56 and $80 \mathrm{~d}$. Overall: calves were given treatments at ages $28,42,56$, and $80 \mathrm{~d} .{ }^{2} \mathrm{CON}=$ no yeast or flavonoids fed; ADY = Candida tropicalis as supplement; FLA = mulberry leaf flavonoids as supplement; $\mathrm{YF}=$ combination of Candida tropicalis and mulberry leaf flavonoids as supplement; VFA = volatile fatty acids. ${ }^{3} \mathrm{SEM}=$ standard error of the mean. 

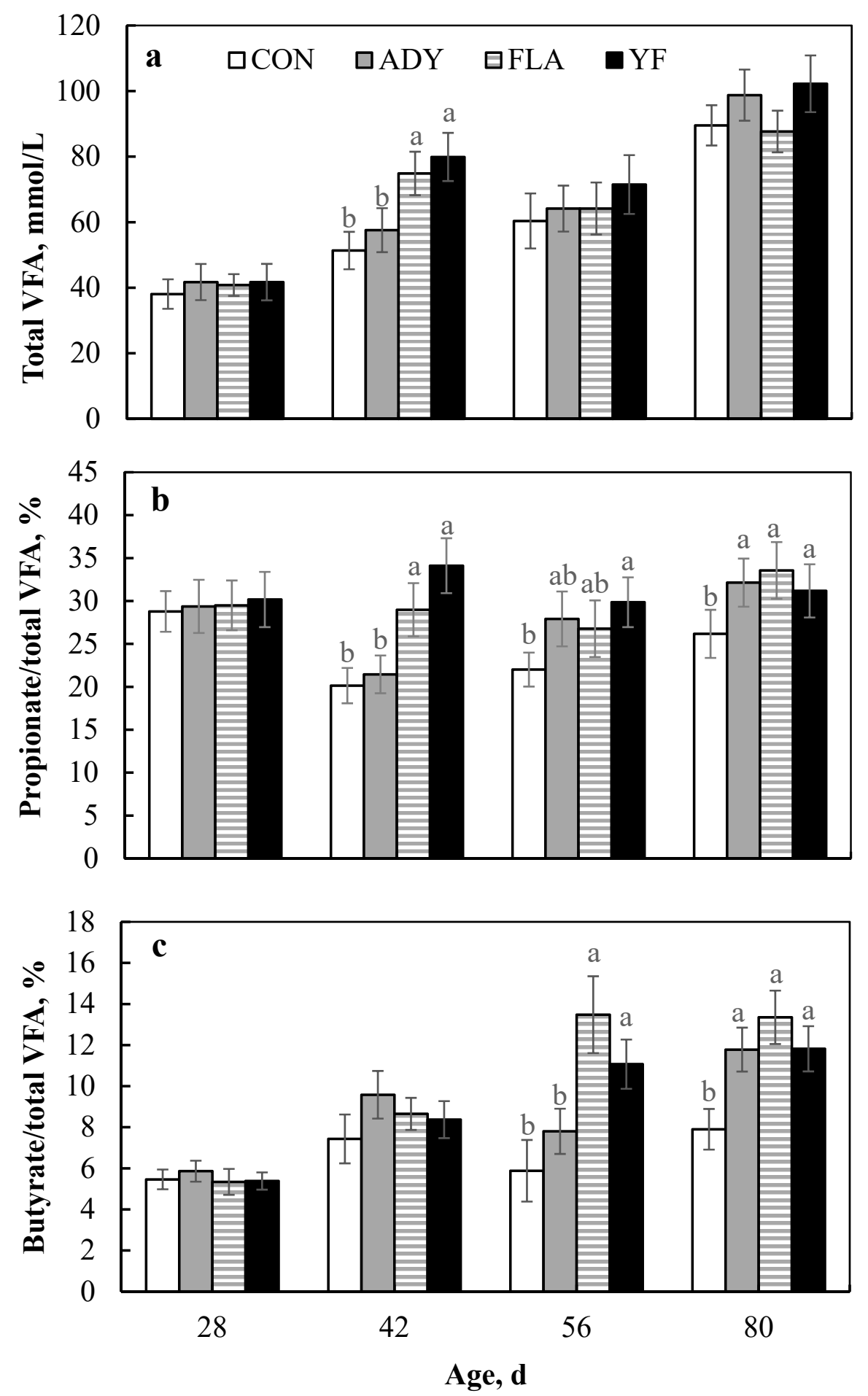

Figure 1. Effects of supplementation with Candida tropicalis and mulberry leaf flavonoids individually or in combination on total volatile fatty acid (VFA) (a) and molar proportions of propionate (b) and butyrate (c) in calves at ages $28,42,56$, and $80 \mathrm{~d}$. CON = no yeast or flavonoids fed; ADY = Candida tropicalis as supplement; FLA = mulberry leaf flavonoids as supplement; YF = combination of Candida tropicalis and mulberry leaf flavonoids as supplement. Within sets of bars, those marked with different letters differ significantly $(p<0.05)$.

\subsection{Blood Biomarkers}

A significant difference was observed for serum $\operatorname{IgG}$ and $\operatorname{IgA}$ concentrations during the pre-weaning, post-weaning, or overall periods ( $p<0.05$; Table 4$)$. The IgG concentrations measured 
for the FLA and YF groups were higher, especially at age $42 \mathrm{~d}$ (Figure 2a), than those for the CON and ADY groups during the pre-weaning period (treatment, treatment $\times$ time, $p<0.05$ ), and were higher compared with the CON group during the overall period (treatment, treatment $\times$ time, $p<0.05$ ). Similar results were observed for IgA concentration, with significant differences observed between the YF group and other groups during the post-weaning (at age $80 \mathrm{~d}$, Figure $2 \mathrm{~b}$ ) (treatment, treatment $\mathrm{X}$ time, $p<0.05$ ) and overall periods (treatment, $p=0.031$ ). Throughout the study period, however, the IgM concentration did not differ among groups $(p>0.05)$. The serum BHBA concentration increased with the age of calves (time, $p<0.05$ ), and BHBA concentrations were higher in the ADY and FLA groups than other groups during the post-weaning period (treatment, treatment $\times$ time, $p<0.05$ ), especially at age $80 \mathrm{~d}$ (Figure 2c). The result for EGF concentration in the CON group was not different compared with the other groups $(p>0.05)$, but there was a significant difference between the FLA and ADY groups during the pre-weaning period (treatment, $p=0.047$ ).

Table 4. Effects of supplementation with Candida tropicalis and mulberry leaf flavonoids individually or in combination on blood parameters in Holstein calves during pre-weaning, post-weaning, and overall periods.

\begin{tabular}{|c|c|c|c|c|c|c|c|c|}
\hline \multirow{2}{*}{ Item $^{1}$} & \multicolumn{4}{|c|}{ Treatment $^{2}$} & \multirow{2}{*}{ SEM $^{3}$} & \multicolumn{3}{|c|}{$p$-Value } \\
\hline & $\mathrm{CON}$ & ADY & FLA & YF & & Treatment & Time & Treatment $\times$ Time \\
\hline \multicolumn{9}{|l|}{$\mathrm{IgG}, \mathrm{g} / \mathrm{L}$} \\
\hline Pre-weaning & $8.93^{b}$ & $9.12^{b}$ & $9.64^{\mathrm{a}}$ & $9.68^{a}$ & 0.19 & 0.032 & 0.341 & 0.008 \\
\hline Post-weaning & 9.45 & 9.62 & 9.74 & 10.15 & 0.27 & 0.120 & 0.258 & 0.364 \\
\hline Overall & $9.09^{b}$ & $9.27^{\mathrm{ab}}$ & $9.72^{\mathrm{a}}$ & $9.78^{\mathrm{a}}$ & 0.19 & 0.041 & 0.003 & 0.052 \\
\hline \multicolumn{9}{|l|}{$\operatorname{IgM}, g / L$} \\
\hline Pre-weaning & 0.84 & 0.83 & 0.83 & 0.86 & 0.01 & 0.438 & 0.204 & 0.511 \\
\hline Post-weaning & 0.85 & 0.91 & 0.90 & 0.90 & 0.16 & 0.085 & 0.338 & 0.213 \\
\hline Overall & 0.84 & 0.86 & 0.85 & 0.87 & 0.01 & 0.255 & 0.111 & 0.302 \\
\hline \multicolumn{9}{|l|}{$\operatorname{Ig} \mathrm{A}, \mathrm{g} / \mathrm{L}$} \\
\hline Pre-weaning & 1.96 & 1.93 & 1.92 & 2.05 & 0.02 & 0.551 & 0.399 & 0.612 \\
\hline Post-weaning & $2.13^{\mathrm{b}}$ & $2.07^{b}$ & $1.95^{\mathrm{b}}$ & $2.40^{\mathrm{a}}$ & 0.02 & 0.013 & 0.632 & 0.021 \\
\hline Overall & $2.02^{b}$ & $1.98^{b}$ & $1.93^{b}$ & $2.20^{\mathrm{a}}$ & 0.04 & 0.031 & 0.031 & 0.333 \\
\hline \multicolumn{9}{|l|}{$\mathrm{BHBA}, \mathrm{mmol} / \mathrm{L}$} \\
\hline Pre-weaning & 0.30 & 0.35 & 0.33 & 0.34 & 0.02 & 0.487 & 0.677 & 0.478 \\
\hline Post-weaning & $0.43^{b}$ & $0.55^{\mathrm{a}}$ & $0.56^{\mathrm{a}}$ & $0.52^{a b}$ & 0.04 & 0.024 & 0.012 & 0.015 \\
\hline Overall & 0.38 & 0.41 & 0.42 & 0.41 & 0.31 & 0.181 & $<0.001$ & 0.406 \\
\hline \multicolumn{9}{|l|}{ EGF, pg/mL } \\
\hline Pre-weaning & $28.83^{a b}$ & $26.47^{b}$ & $35.38^{a}$ & $28.04^{\mathrm{ab}}$ & 1.49 & 0.047 & 0.193 & 0.180 \\
\hline Post-weaning & 30.23 & 28.29 & 33.44 & 29.57 & 2.07 & 0.217 & 0.418 & 0.321 \\
\hline Overall & 29.44 & 27.23 & 34.89 & 28.94 & 1.80 & 0.161 & 0.586 & 0.606 \\
\hline
\end{tabular}

${ }^{\mathrm{a}, \mathrm{b}}$ Mean values within a row with different superscripts differ significantly $(p<0.05) .{ }^{1}$ Pre- and post-weaning: calves were given treatments at ages 28 and $42 \mathrm{~d}$, and at ages 56 and $80 \mathrm{~d}$. Overall: calves were given treatments at ages $28,42,56$, and $80 \mathrm{~d} .{ }^{2} \mathrm{CON}=$ no yeast or flavonoids fed; ADY = Candida tropicalis as supplement; FLA = mulberry leaf flavonoids as supplement; $\mathrm{YF}=$ combination of Candida tropicalis and mulberry leaf flavonoids as supplement; $\mathrm{BHBA}=\beta$-hydroxybutyric acid; EGF $=$ epidermal growth factor. ${ }^{3} \mathrm{SEM}=$ standard error of the mean. 

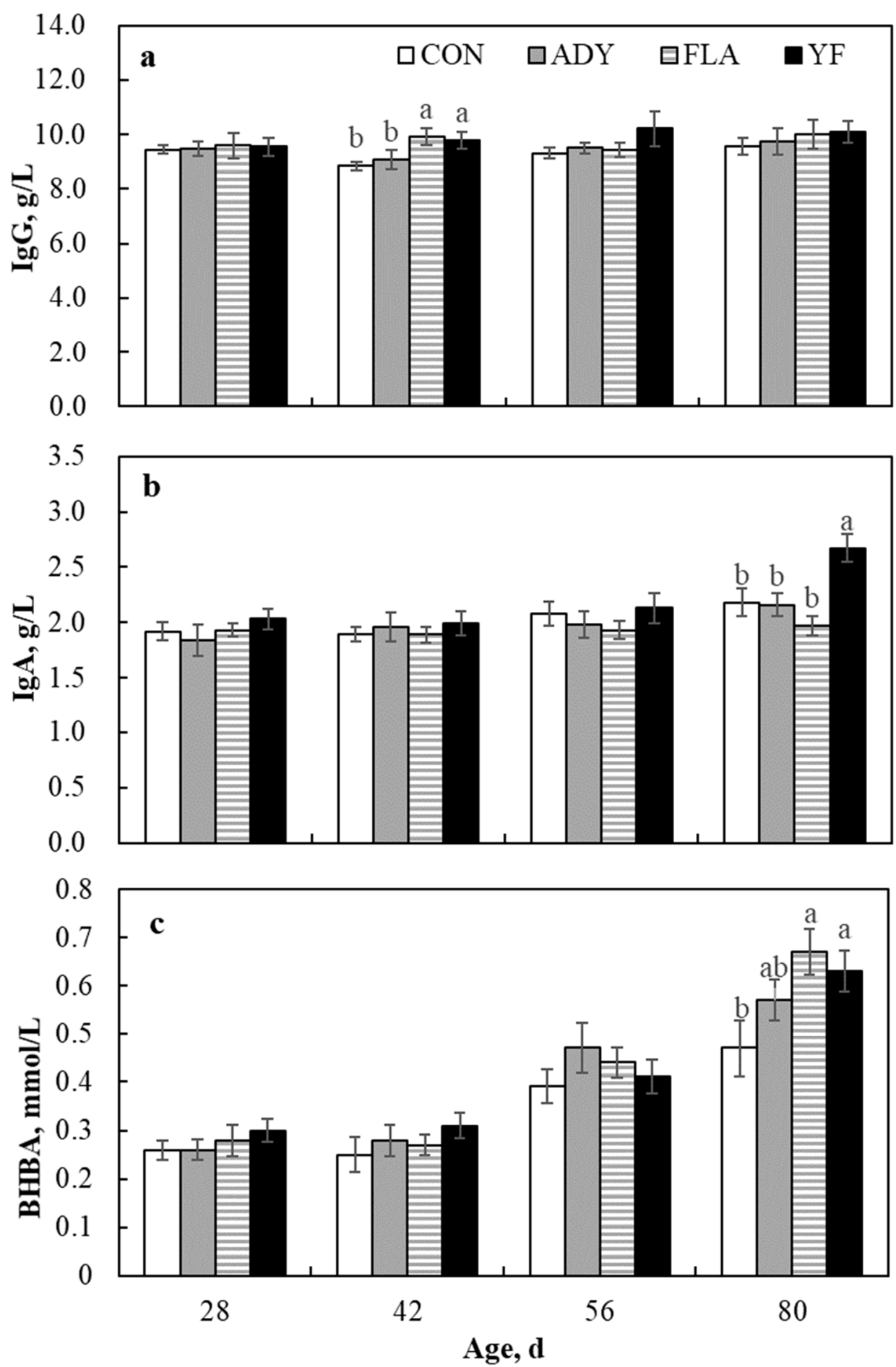

Figure 2. Effects of supplementation with Candida tropicalis and mulberry leaf flavonoids individually or in combination on serum concentrations of $\operatorname{IgG}(\mathbf{a}), \operatorname{IgA}(\mathbf{b})$, and $\beta$-hydroxybutyric acid (BHBA, (c)) in calves at ages $28,42,56$, and $80 \mathrm{~d}$. CON = no yeast or flavonoids fed; ADY = Candida tropicalis as supplement; FLA = mulberry leaf flavonoids as supplement; YF = combination of Candida tropicalis and mulberry leaf flavonoids as supplement. Within sets of bars, those marked with different letters differ significantly $(p<0.05)$. 


\section{Discussion}

\subsection{Growth and Health Performance}

Flavonoids have been widely investigated and increasingly used in monogastric species and ruminant production systems, and have improved growth performance, health, and rumen fermentation conditions [24]. Some previous studies have reported that yeast is an effective alternative to antibiotics in ruminants [25,26], but these trials reported little benefit to calf performance [27,28]. Similar to the results of our present study, oral administration of $C$. tropicalis did not improve DM intake or ADG of calves [28]. However, flavonoids or a mixture of flavonoids and yeast had beneficial effects on ADG and feed efficiency of calves during the post-weaning period, indicating that flavonoid supplementation may help alleviate stress during weaning [29]. Less stressful and earlier weaning improves calf health and the economic impact of raising calves. Compared with flavonoids alone, however, the combined use of $C$. tropicalis and flavonoids did not have a synergistic effect. Balcells et al. [24] found that feeding flavonoids had little effect on ADG (1.16 vs. $1.09 \mathrm{~kg} / \mathrm{d})$ and feed conversion ratio $(6.80$ vs. $7.28 \mathrm{~kg} / \mathrm{kg}, p>0.05)$ in adult heifers. This discrepancy may be attributed to the fact that the epithelium in newborn animals is comprised mainly of vacuolated epithelial cells [30,31], which absorb flavonoids or metabolites that retain a flavonol structure, and these cells are not present in older animals [32]. Flavonoids have structures similar to those of estrogenic hormones, and they share certain functional characteristics, such as modulation of expression and activity of key lipid and carbohydrate metabolic enzymes, which enhance anabolism [17,18]. Mechanistically, this may explain why flavonoid supplementation contributes to improved ADG and feed efficiency for younger animals, as we observed in the present study. Future work will be required to substantiate these findings in detail using larger sample sizes.

Although C. tropicalis was previously documented as an opportunistic pathogen [3], it is commonly detected in the gastrointestinal tract of healthy humans [4,5] and contributes to the digestion of fibrous material in production animals [6,7]. Magalhães et al. [1] reported a decrease in fecal scores when calves were fed S. cerevisiae. So far, however, the effects of $C$. tropicalis on health conditions have not been investigated in ruminants. In the present study, supplementing calves with $C$. tropicalis did not improve animal health compared with flavonoids. Flavonoids may decrease fecal scores in calves by disrupting pathogen cell membrane integrity and metabolism, thereby inhibiting pathogen growth. Oral administration of a mixture of yeast and flavonoids yielded the same effect compared with flavonoids alone, suggesting that feeding calves a combination of yeast and flavonoids does not have a synergistic effect.

\subsection{Rumen Fermentation Parameters}

We found that rumen $\mathrm{pH}$ was not significantly affected by supplementation with flavonoids or yeast or the combination of both during pre-weaning, post-weaning, and the overall period, which is consistent with the findings of Oskoueian et al. [33]. An in vitro study conducted by Seradj et al. [34] showed that flavonoids supplementation did not influence the $\mathrm{pH}$ of rumen fluid from steers. Bayat et al. [35] reported that supplementation with live yeast strains had little effect on rumen fluid $\mathrm{pH}$, which was in agreement with the findings of Aikman et al. [36] showing that supplementation with Megasphaera elsdenii did not alter the rumen $\mathrm{pH}$ in early lactating dairy cows. Some research suggests that rumen $\mathrm{pH}$ is affected not only by differences in feed, saliva, and rate of passage in the rumen, but also by fermentation products (e.g., $\mathrm{NH}_{3}-\mathrm{N}$, VFA, and lactic acid) [36]. In the present study, the concentrations of $\mathrm{NH}_{3}-\mathrm{N}$ and acetate were minimally affected throughout the experiment, which may contribute to the observed constant rumen $\mathrm{pH}$ and fermentation conditions. Moreover, the molar proportions of propionate and total VFA concentration were significant different across groups during certain specific periods, suggesting that yeast or flavonoids can be utilized as fermentable substrates. For flavonoids, some research suggests that they can be readily degraded by microbes, and their derivatives enhance rumen microbial activity in adult ruminants [14]. Increases in 
propionate concentration could be attributed to enhanced growth of propionate-producing bacteria in the rumen [14], and consequently decreased acetate/propionate ratio in rumen. Smith et al. [37] found phenolic acids and nonaromatic fermentation products in the rumen as the result of microbial degradation of flavonoids. Thus, these byproducts could play a role as alternative carbon sources for rumen microbes. On the other hand, diet supplement with flavonoids increases the butyrate concentration in the rumen, and butyrate is regarded as a signaling molecule that indirectly stimulates epithelial proliferation [38]. This suggests that flavonoids may contribute to the rumen development, but the mechanism remains unclear. However, rumen VFA responses to yeast supplementation are inconsistent [35,39]. For example, Kumprechtová et al. [27] found that addition of live yeast to the diet increased rumen VFA concentrations, whereas Bayat et al. [35] demonstrated no influence of yeast on rumen VFA concentrations for lactating cows fed grass silage diets. Little research has been published concerning the effect of $C$. tropicalis supplementation on rumen VFA production. In the current study, adding C. tropicalis alone to the diet did not increase VFA concentrations, but rather increased the propionate concentration, although the combination of yeast and flavonoids had greater effects. Marrero et al. [7] also established that C. tropicalis has a greater ability to digest soluble carbohydrates compared with S. cerevisiae, and thus $C$. tropicalis may convert more substrates to glucose, which is needed by younger animals.

\subsection{Blood Parameters}

In the current study, supplementation with mulberry leaf flavonoids alone or combined with C. tropicalis reduced the fecal scores. This coincided with increased concentrations of $\operatorname{IgG}, \operatorname{IgM}$, and IgA over the course of the study. It has been widely recognized that immunoglobulin concentration can be used as an indicator of calf health [40]. IgA has the potential to reduce pathogenic bacteria by combination with innate nonspecific defense mechanisms. IgM plays an important role at the initial stage of antibody response. In the present study, supplementation with a combination of yeast and flavonoids resulted in increased concentrations of serum IgG and IgA, suggesting that the combined supplementation may help stimulate the immune response more than either supplement alone. The mechanism by which phytogenic feed additives increase serum immunoglobulin concentrations is largely unknown. It is possible that bioactive molecules derived from flavonoids (e.g., flavone, flavonols, etc.) act as additional ligands for Fc receptors, which bind to IgG and stimulate the immune response [41]. Probiotics as immunomodulators interact with the intestinal resident microflora and epithelial and immune cells to stimulate immune function, leading to antibody production [42]. Higher levels of immunomodulators increase antibody production, which neutralizes antigen or pathogenic bacteria via a systemic immune response that reduces stress responses and increases the growth of younger animals. However, the mechanisms by which yeast and flavonoids interactively affect immune function remain poorly defined.

Butyrate is reportedly converted to BHBA in the rumen wall before appearing in the portal circulation [10]. Therefore, as the rumen wall is metabolically nonfunctional in newborn calves, the concentration of BHBA might be relatively low compared with that in adult ruminants. The concentration of BHBA in calves increased over time, and supplementation with yeast or flavonoids alone yielded the same result for the concentration of butyrate. This change suggests that rumen functional development is enhanced by supplementation with yeast and flavonoids, and that supplementation also improves the energy source from glucose change to VFA [43]. Serum EGF concentration was not affected by supplementation with flavonoids or yeast or a combination of both. Interestingly, calves fed flavonoids had higher serum EGF concentrations than those fed yeast during the pre-weaning period. This may be attributed to the molecular structure of flavonoids being similar to estradiol, which can regulate the expression of EGF and EGF receptors, and to C. Tropicalis, which in the gastrointestinal tract may influence the absorption of EGF. 


\section{Conclusions}

Supplementation with C. tropicalis or flavonoids increased the proportion of propionate among rumen fermentation products, but supplementation with $C$. tropicalis had limited effects on increasing growth performance and decreasing fecal scores compared with flavonoids supplementation. Moreover, the combination of $C$. tropicalis and flavonoids did not have a synergistic effect on health or rumen fermentation compared with use of flavonoids alone in pre- and post-weaning calves. Additionally, a time effect or interaction between treatment and time was found for ADG, feed efficiency, total volatile fatty acid concentration, and proportion of propionate in calves. Further investigation is needed to illuminate the mechanism of flavonoid supplementation to promote rumen development and microbial composition in calves.

Author Contributions: Conceptualization, Q.D., and Y.T.; methodology, Q.D., Y.T., and C.Y; software, C.Y.; formal analysis, C.Y.; investigation, C.Y.; resources, J.M., L.K., and C.Y.; data curation, Y.T., and C.Y.; writing-original draft preparation, C.Y.; writing-review and editing, Q.D., Y.T., and L.D.; supervision, B.S., and Y.T.; project administration, Q.D., and Y.T.; funding acquisition, Q.D., and Y.T.

Funding: This study was supported by Earmarked Fund for Beijing Dairy Industry Innovation Consortium of Agriculture Research System (BAIC06-2019), Chinese Academy of Agricultural Science and Technology Innovation Project (CAAS-XTCX2016011-01) and The Agricultural Science and Technology Innovation Program (CAAS-ASTIP-2017-FRI-04).

Acknowledgments: We gratefully acknowledge Professor Kevin Harvatine of the Department of Animal Science, Pennsylvania State University (University Park, PA, USA), for his comments and revision of the manuscript.

Conflicts of Interest: The authors declare no conflict of interest. All authors read and approved the final manuscript for publication. The sponsors had no role in the design, execution, interpretation, or writing of the study.

\section{References}

1. Magalhães, V.J.A.; Susca, F.; Lima, F.S.; Branco, A.F.; Yoon, I.; Santos, J.E.P. Effect of feeding yeast culture on performance, health, and immunocompetence of dairy calves. J. Dairy Sci. 2008, 91, 1497-1509. [CrossRef]

2. Gudlaugsson, O.; Gillespie, S.; Lee, K.; Berg, J.V.; Hu, J.; Messer, S.; Herwaldt, L.; Pfaller, M.; Diekema, D. Attributable mortality of nosocomial candidiasis, revisited. Clin. Infect. Dis. 2003, 37, 1172-1177. [CrossRef] [PubMed]

3. Silva, S.; Megri, M.; Henriques, M.; Oliveira, R.; Williams, D.W.; Azeredo, J. Candida glabrata, Candida parapsilosis and Candida tropicalis: Biology, epidemiology, pathogenicity and antifungal resistance. Fems. Microbiol. Rev. 2011, 36, 288-305. [CrossRef] [PubMed]

4. Moran, G.; Coleman, D.; Sullivan, D. An Introduction to the Medically Important Candida Species, 2nd ed.; ASM Press: Washington, DC, USA, 2012; pp. 11-25.

5. Hallen-Adams, H.E.; Kachman, S.D.; Kim, J.; Legge, R.M.; Martinez, I. Fungi inhabiting the healthy human gastrointestinal tract: A diverse and dynamic community. Fungal. Ecol. 2015, 15, 9-17. [CrossRef]

6. Zhang, W.J.; Xu, Z.R.; Zhao, S.H.; Sun, J.Y.; Yang, X. Development of a microbial fermentation process for detoxification of gossypol in cottonseed meal. Anim. Feed Sci. Technol. 2007, 135, 176-186. [CrossRef]

7. Marrero, Y.; Castillo, Y.; Burrola-Barraza, M.E.; Lobaina, T.; Rosa, C.A.; Ruiz, O.; Gonzalez-Rodriguez, E.; Basso, L.C. Morphological, biochemical and molecular identification of the yeast Levica 25: A Potential Ruminal Microbial Additive. Glob. Vet. 2011, 7, 60-85.

8. Marrero, Y.; Castillo, Y.; Ruiz, O.; Burrola, E.; Angulo, C. Feeding of yeast (Candida spp.) improves in vitro ruminal fermentation of fibrous substrates. J. Integr. Agric. 2015, 14, 514-519. [CrossRef]

9. Timmerman, H.M.; Koning, C.J.M.; Mulder, L.; Rombouts, F.M.; Beynen, A.C. Monostrain, multistrain and multispecies probiotics-A comparison of functionality and efficacy. Int. J. Food Microbiol. 2004, 96, 219-233. [CrossRef]

10. Bayatkouhsar, J.; Tahmasebi, A.M.; Naserian, A.A.; Mokarram, R.R.; Valizadeh, R. Effects of supplementation of lactic acid bacteria on growth performance, blood metabolites and fecal coliform and lactobacilli of young dairy calves. Anim. Feed Sci. Technol. 2013, 186, 1-11. [CrossRef]

11. Rochfort, S.; Parker, A.J.; Dunshea, F.R. Plant bioactives for ruminant health and productivity. Phytochemistry 2008, 69, 299-322. [CrossRef] 
12. Stoldt, A.K.; Derno, M.; Nurnberg, G.; Weitzel, J.M.; Otten, W.; Starke, A.; Wolffram, S.; Metges, C.C. Effects of a 6-wk intraduodenal supplementation of quercetin reduces indicators of liver damage in periparturient dairy cows. J. Dairy Sci. 2015, 98, 4509-4520. [CrossRef] [PubMed]

13. Chen, D.D.; Chen, X.L.; Tu, Y.; Wang, B.; Lou, C.; Ma, T.; Diao, Q.Y. Effects of mulberry leaf flavonoid and resveratrol on methane emission and nutrient digestion in sheep. Anim. Nutr. 2015, 1, 362-367. [CrossRef] [PubMed]

14. Berger, L.M.; Wein, S.; Blank, R.; Metges, C.C.; Wolffram, S. Bioavailability of the flavonol quercetin in cows after intraruminal application of quercetin aglycone and rutin. J. Dairy Sci. 2012, 95, 5047-5055. [CrossRef] [PubMed]

15. Stoldt, A.K.; Derno, M.; Das, G.; Weitzel, J.M.; Wolffram, S.; Metges, C.C. Effects of rutin and buckwheat seeds on energy metabolism and methane production in dairy cows. J. Dairy Sci. 2016, 99, 2161-2168. [CrossRef] [PubMed]

16. Besle, J.M.; Viala, D.; Martin, B.; Pradel, P.; Meunier, B.; Berdague, J.L.; Fraisse, D.; Lamaison, J.L.; Coulon, J.B. Ultraviolet-absorbing compounds in milk are related to forage polyphenols. J. Dairy Sci. 2010, 93, $2846-2856$. [CrossRef]

17. Kobayashi, Y.; Miyazawa, M.; Kamel, A.; Abe, K.; Kojima, T. Ameliorative effects of mulberry (Morus alba L.) leaves on hyperlipidemia in rats fed a high-fat diet: Induction of fatty acid oxidation, inhibition of lipogenesis, and suppression of oxidative stress. Biosci. Biotechnol. Biochem. 2010, 74, 2385-2395. [CrossRef]

18. Berger, L.M.; Blank, R.; Zorn, F.; Wein, S.; Metges, C.C.; Wolffram, S. Ruminal degradation of quercetin and its influence on fermentation in ruminants. J. Dairy Sci. 2015, 98, 5688-5698. [CrossRef]

19. Chung, Y.H.; Walker, N.D.; McGinn, S.M.; Beauchemin, K.A. Differing effects of 2 active dried yeast (Saccharomyces cerevisiae) strains on ruminal acidosis and methane production in nonlactating dairy cows. J. Dairy Sci. 2011, 94, 2431-2439. [CrossRef]

20. Jiang, Y.; Ogunade, I.M.; Arriola, K.G.; Qi, M.; Vyas, D.; Staples, C.R.; Adesogan, A.T. Effects of the dose and viability of Saccharomyces cerevisiae. 2. Ruminal fermentation, performance of lactating dairy cows, and correlations between ruminal bacteria abundance and performance measures. J. Dairy Sci. 2017, 100, 8102-8118. [CrossRef]

21. Heinrichs, A.J.; Jones, C.M.; Heinrichs, B.S. Effects of mannan oligosaccharide or antibiotics in neonatal diets on health and growth of dairy calves. J. Dairy Sci. 2003, 86, 4064-4069. [CrossRef]

22. Dong, L.F.; Zhang, W.B.; Zhang, N.F.; Tu, Y.; Diao, Q.Y. Feeding different dietary protein to energy ratios to Holstein heifers: Effects on growth performance, blood metabolites and rumen fermentation parameters. J. Anim. Physiol. Anim. Nutr. 2016, 101, 30-37. [CrossRef] [PubMed]

23. Cao, Y.C.; Yang, H.J. Ruminal digestibility and fermentation characteristics in vitro of fenugreek and alfalfa hay combination with or without the inoculation of Neocallimastix sp. YAK11. Anim. Feed Sci. Technol. 2011, 169, 53-60. [CrossRef]

24. Balcells, J.; Aris, A.; Serrano, A.; Seradj, A.R.; Crespo, J.; Devant, M. Effects of an extract of plant flavonoids (Bioflavex) on rumen fermentation and performance in heifers fed high-concentrate diets. J. Anim. Sci. 2012, 90, 4975-4984. [CrossRef] [PubMed]

25. Durmic, Z.; Moate, P.J.; Eckard, R.; Revell, D.K.; Williams, R.; Vercoe, P.E. In vitro screening of selected feed additives, plant essential oils and plant extracts for rumen methane mitigation. J. Sci. Food Agric. 2014, 94, 1191-1196. [CrossRef] [PubMed]

26. Elghandour, M.M.Y.; Chagoyán, J.C.V.; Salem, A.Z.M.; Kholif, A.E.; Castaneda, J.S.M.; Camacho, L.M.; Buendia, G. In vitro fermentative capacity of equine fecal inocula of nine fibrous forages in presence of different doses of Saccharomyces cerevisiae. J. Equine Vet. Sci. 2014, 34, 619-625. [CrossRef]

27. Kumprechtová, D.; Illek, J.; Julien, C.; Homolka, P.; Jancik, F.; Auclair, E. Effect of live yeast (Saccharomyces cerevisiae.) supplementation on rumen fermentation and metabolic profile of dairy cows in early lactation. J. Anim. Physiol. Anim. Nutr. 2019, 103, 447-455.

28. Geiger, A.J.; Ward, S.H.; Williams, C.C.; Rude, B.J.; Cabrera, C.J.; Kalestch, K.N.; Voelz, B.E. Short communication: Effects of increasing protein and energy in the milk replacer with or without direct-fed microbial supplementation on growth and performance of preweaned Holstein calves. J. Dairy Sci. 2014, 97, 7212-7219. [CrossRef] 
29. Yaghoubi, S.M.J.; Ghorbani, G.R.; Rahmani, H.R.; Nikkhah, A. Growth, weaning performance and blood indicators of humoral immunity in Holstein calves fed supplemental flavonoids. J. Anim. Physiol. Anim. Nutr. 2008, 92, 456-462. [CrossRef]

30. Bainter, K. Vacuolation in the young. In Biology of the Intestine in Growing Animals; Zabielski, R., Gregory, P.C., Westrom, B., Eds.; Elsevier: Amsterdam, The Netherlands, 2002; pp. 55-110.

31. Blum, J.W. Nutritional physiology of neonatal calves. J. Anim. Physiol. Anim. Nutr. 2006, 90, 1-11. [CrossRef]

32. Maciej, J.; Schäff, C.T.; Kanitz, E.; Tuchscherer, A.; Bruckmaier, R.M.; Wolffram, S.; Hammon, H.M. Bioavailability of the flavonol quercetin in neonatal calves after oral administration of quercetin aglycone or rutin. J. Dairy Sci. 2015, 98, 3906-3917. [CrossRef]

33. Oskoueian, E.; Abdullah, N.; Oskoueian, A. Effects of flavonoids on rumen fermentation activity, methane production, and microbial population. BioMed Res. Int. 2013. under review. [CrossRef] [PubMed]

34. Seradj, A.R.; Abecia, L.; Crespo, J.; Villalba, D.; Fondevila, M.; Balcells, J. The effect of Bioflavex and its pure flavonoid components on in vitro fermentation parameters and methane production in rumen fluid from steers given high concentrate diets. Anim. Feed Sci. Technol. 2014, 197, 85-91. [CrossRef]

35. Bayat, A.R.; Kairenius, P.; Stefański, T.; Leskinen, H.; Comtet-Marre, S.; Forano, E.; Chaucheyras-Durand, F.; Shingfield, K.J. Effect of camelina oil or live yeasts (Saccharomyces cerevisiae) on ruminal methane production, rumen fermentation, and milk fatty acid composition in lactating cows fed grass silage diets. J. Dairy Sci. 2014, 98, 3166-3181. [CrossRef] [PubMed]

36. Aikman, P.C.; Henning, P.H.; Humphries, D.J.; Horn, C.H. Rumen pH and fermentation characteristics in dairy cows supplemented with Megasphaera elsdenii NCIMB 41125 in early lactation. J. Dairy Sci. 2010, 94, 2840-2849. [CrossRef] [PubMed]

37. Smith, A.H.; Zoetendal, E.; Mackie, R.I. Bacterial mechanisms to overcome inhibitory effects of dietary tannins. Microb. Ecol. 2005, 50, 197-205. [CrossRef] [PubMed]

38. Gorka, P.; Kowalski, Z.M.; Pietrzak, P.; Kotunia, A.; Kiljanczyk, R.; Flaga, J.; Holst, J.J.; Guilloteau, P.; Zabielski, R. Effect of sodium butyrate supplementation in milk replacer and starter diet on rumen development in calves. J. Physiol. Pharm. 2009, 60, 47-53.

39. Hristov, A.N.; Varga, G.; Cassidy, T.; Long, M.; Heyler, K.; Karnati, S.K.R.; Corl, B.; Hovde, C.J.; Yoon, I. Effect of Saccharomyces cerevisiae fermentation product on ruminal fermentation and nutrient utilization in dairy cows. J. Dairy Sci. 2009, 93, 682-692. [CrossRef]

40. Sun, P.; Wang, J.Q.; Zhang, H.T. Effects of Bacillus Subtilis Natto on performance and immune function of preweaning calves. J. Dairy Sci. 2010, 93, 5851-5855. [CrossRef]

41. Nimmerjahn, F.; Ravetch, J.V. Antibody-mediated modulation of immune responses. Immunol. Rev. 2010, 236, 265-275. [CrossRef]

42. Kaburagi, T.; Yamano, T.; Fukushima, Y.; Yoshino, H.; Mito, N.; Sato, K. Effect of Lactobacillus johnsonii La1 on immune function and serum albumin in aged and malnourished aged mice. Nutrition 2007, 23, 342-350. [CrossRef]

43. Quigley, J.R.; Caldwell, L.A.; Sinks, G.D.; Heitmann, R.N. Changes in blood glucose, nonesterified fatty acids, and ketones in response to weaning and feed intake in young calves. J. Dairy Sci. 1991, 74, 250-257. [CrossRef]

(C) 2019 by the authors. Licensee MDPI, Basel, Switzerland. This article is an open access article distributed under the terms and conditions of the Creative Commons Attribution (CC BY) license (http://creativecommons.org/licenses/by/4.0/). 